University of Nebraska - Lincoln

DigitalCommons@University of Nebraska - Lincoln

\title{
Connecting Soil to the Cloud: A Wireless Underground Sensor Network Testbed
}

John Tooker

University of Nebraska-Lincoln, jtooker@cse.unl.edu

Xin Dong

University of Nebraska-Lincoln, xdong@cse.unl.edu

Mehmet C. Vuran

University of Nebraska-Lincoln, mcvuran@cse.unl.edu

Suat Irmak

University of Nebraska-Lincoln, suat.irmak@unl.edu

Follow this and additional works at: https://digitalcommons.unl.edu/cseconfwork

Part of the Computer Sciences Commons

Tooker, John; Dong, Xin; Vuran, Mehmet C.; and Irmak, Suat, "Connecting Soil to the Cloud: A Wireless Underground Sensor Network Testbed" (2012). CSE Conference and Workshop Papers. 204.

https://digitalcommons.unl.edu/cseconfwork/204

This Article is brought to you for free and open access by the Computer Science and Engineering, Department of at DigitalCommons@University of Nebraska - Lincoln. It has been accepted for inclusion in CSE Conference and Workshop Papers by an authorized administrator of DigitalCommons@University of Nebraska - Lincoln. 


\section{Connecting Soil to the Cloud: A Wireless Underground Sensor Network Testbed}

\author{
John Tooker, Xin Dong and Mehmet C. Vuran \\ Cyber-Physical Networking Laboratory \\ Department of Computer Science \& Engineering \\ University of Nebraska-Lincoln, Lincoln, NE 68588 \\ Email: \{jtooker, xdong, mcvuran\}@ cse.unl.edu
}

\author{
Suat Irmak \\ Biological System Enginering Department \\ Univeristy of Nebraska-Lincoln, Lincoln, NE 68588 \\ Email: sirmak2@unl.edu
}

\begin{abstract}
In this demo, a novel underground communication system and an online underground sensor network testbed is demonstrated. The underground communication system, developed in the Cyber-physical Networking (CPN) Laboratory at the University of Nebraska-Lincoln, includes an underground antenna that is tailored to mitigate the adverse effects of soil on underground communication. An online connection is established with the CPN underground sensor network testbed that is located at Clay Center, Nebraska. The underground sensor network testbed consists of a network of underground communication systems equipped with soil moisture sensors and a mobile data harvesting unit equipped with cellular communication capabilities. Real-time soil moisture data delivery from Nebraska to Korea is demonstrated.
\end{abstract}

\section{INTRODUCTION}

Excessive, wasted water has prompted the creation of the Top 10 Water Challenges of Nebraska [9]. Approximately $70 \%$ of the world's water usage is related to agriculture [8], thus, more efficient irrigation solutions promise a large benefit for farmers, consumers and the environment. The demand for reducing water consumption encourages development of precision agriculture (PA) techniques, which focus on the existence of in-field variability of natural components, including chemical leaching, runoff, drainage, water content, nutrients, and soil components [3], [4]. One of the examples of PA is the Variable Rate Irrigation (VRI) system from Valmont Industries [10], which controls the irrigation rate at different zones in a field. This system allows for the flow of each sprinkler head to be adjusted, which gives a virtual dartboard of control, where each cell can get as much or little water as needed. Thus timing and amount of irrigation can be controlled across a field.

Precision irrigation hardware techniques are already developed, but determination of the exact amount of water needed in a zone of field is the main challenge. Currently, fields are analyzed only once, and irrigation systems are programmed according to these results [1]. However, due to the fact that the environment is highly variable and unpredictable [5], a real-time system to monitor the soil and control the irrigation system has the potential to yield even greater water savings.

Current research in this area suggests promising results. In [11], the effect of using a wireless sensor network to aid

This work is supported in part by the National Science Foundation CAREER Award CNS-0953900.

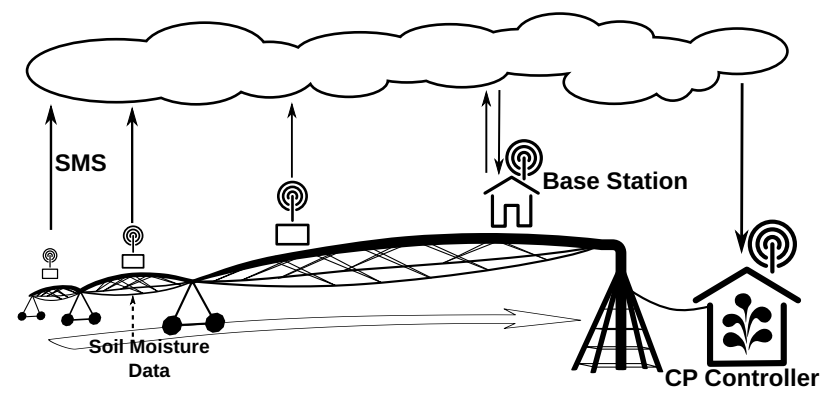

Fig. 1: Overview of the system: aboveground motes attached to the centerpivot collect and relay soil moisture messages from underground motes to the base station.

in irrigation is examined. Their approach uses a permanent aboveground wireless sensor networks (WSN) deployed in a field. This allows for real-time soil moisture collection. A portion of the field was watered using traditional means, the other half was watered adaptively using the data collected by the WSN. The goal of this experiment is to keep soil moisture tension (which is related to how well crops can absorb moisture) in an optimal range. The results of the experiment showed that the adaptive half of the field stayed within range more often than the control half, rarely going beyond the set threshold. However, the aboveground motes are susceptible to destruction by farm equipment. In addition, soil moisture sensors need to be installed early in the growing season and need to be removed before harvest, adding additional time and labor requirements.

In our previous research, we examed the usage of wireless underground sensor networks (WUSNs) to monitor the soil qualities, especially soil moisture to facilitate PA [2], [7]. These networks consist of wirelessly-connected underground sensor nodes that communicate through soil. For the autonomous PA, WUSNs provide an adaptable and efficient cyber-physical system (CPS) that provides timely information of the soil condition with high granularity [6]. Compared with satellites and aerial remote sensing, WUSNs can provide more direct and precise information about some of the soil conditions. In addition, the operation cost of WUSNs is far less than these other techniques [11]. Unlike wired sensor networks, which need to be deployed and removed frequently 
during the process of planting, WUSNs are deployed in the ground at a safe depth and do not interfere with agriculture machinery operations, such as tillage practices.

In this demonstration, we describe a system that collects soil moisture information in a field and relays data to a control system through cellular phone network. Thus, the soil moisture status of the field is provided to the farmers in real-time. The cellular network is employed in our system due to its highly availability such that no further infrastructure is needed.

The implementation details are presented in Section II and the demonstration is provided in Section III, followed by conclusions in Section IV.

\section{IMPLEMENTATION}

In the demonstration, an aboveground mote on a centerpivot irrigation system is employed to collect the real-time data via a WUSN and the information is relayed to the base station through short message service (SMS) messages (a.k.a. text messages). In the envisioned system, the data collected at the base station are utilized to control the speed of the center-pivot, and thus, adjust the irrigated water. This concept is shown in Fig. 1. The interface between the mote and the center-pivot is:

- Mote to SMS (text messaging)

- SMS to center-pivot controller

The first part of the interface uses a Mica2 mote connected to a GSM (Cellular) radio. The base station mote facilitates this communication and translation. The second part receives SMS messages and forward them to the center-pivot's controller. This portion is often implemented by center-pivot manufacturers or controller add-ons.

Though in our demonstration the data are displayed but the center-pivot is not controlled, the system interfaces with any controller that will accept SMS control.

In this section, the implementation of the system is described in detail. The hardware is introduced in Section II-A and the program procedure is introduced in Section II-B.

\section{A. Hardware}

The hardware of the system includes WSN motes, soil moisture sensors and cellular modems. In our system, Mica2 motes are employed as the sensor mote platform. For the underground motes, a soil moisture sensor is connected to each mote. The readings of the sensor are obtained via a GPIO port of Mica2.

The hardware for the aboveground motes and base station mote is shown in Fig. 2. In addition to the Mica2 mote, a GSM chip is employed for the SMS message communication. A custom printed circuit board (PCB) was created to interface the two devices (Mica2 mote and GSM chip), as well as power each devices at the appropriate voltage.

As shown in our previous study [2], antenna design is imperative to the success of WUSN applications. In our system, A Yagi antenna is adapted for the aboveground mote due to its high directivity $(10 \mathrm{~dB})$. For the underground motes,

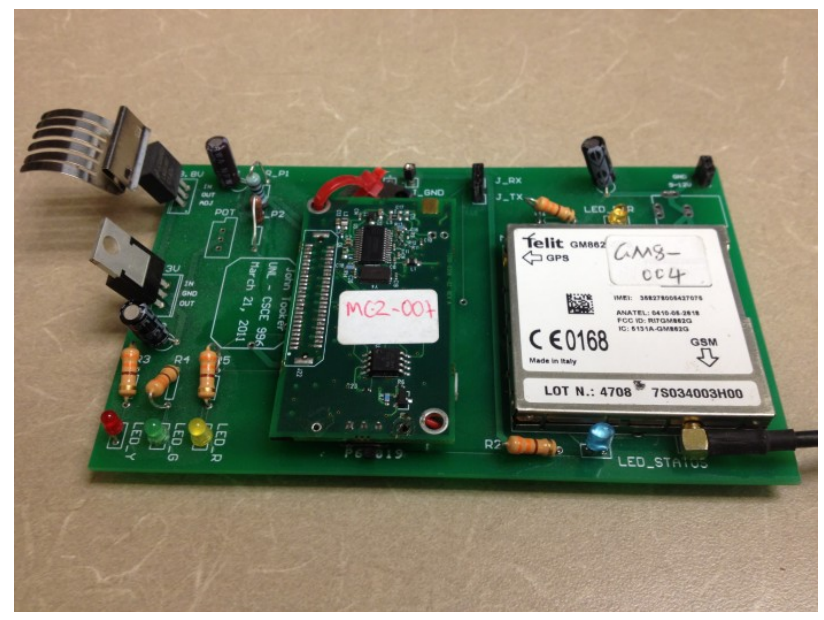

Fig. 2: The aboveground mote with Mica2 and the GSM chip.

an underground antenna is specifically designed for our application. This antenna has good performance over a wide range of soil moisture levels.

\section{B. Program Procedure}

The program of the system deals with mote-to-mote communications to collect soil moisture data, converting soil moisture values to center-pivot control commands and Sending SMS messages.

1) Mote to Mote Message: Aboveground Mica2 motes set on the center-pivot act as relay nodes. They gather soil moisture readings from underground motes via TinyOS wireless messages and send this information to a Mica2 base station mote via SMS messages. Due to the characteristics of the underground-to-aboveground channel, the communication distance between the underground sensor motes and the aboveground relay nodes is limited [2]. However, the GSM module on the relay motes can relay the messages to a very long distance.

2) Moisture to Speed Conversion: As the base station mote receives moisture updates, it can decide on a more appropriate travelling speed of the center-pivot, which determines the irrigation rate. This can be implemented by a lookup table (or conversion equation) that is preprogrammed at this mote.

3) Mote to SMS Messages: Every time a new speed is chosen by the base station mote, an SMS message is sent to the controller of the center-pivot. These messages would be formated using the application programming interface (API) provided by the manufacturer. Direction is also included, either clockwise or counterclockwise.

\section{DEMONSTRATION}

Our experiments are carried out in the South Central Agricultural Laboratory (SCAL) of University of Nebraska-Lincoln at Clay Center, Nebraska. As shown in Fig. 3, underground sensor motes are buried in a corn field. The burial depth is chosen to be $0.4 \mathrm{~m}$ so that the machinery operations will not destroy the motes. An aboveground relay mote is employed 


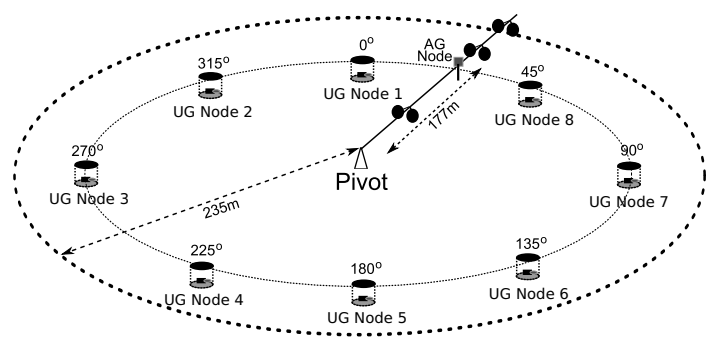

Fig. 3: The setup of the demonstration.

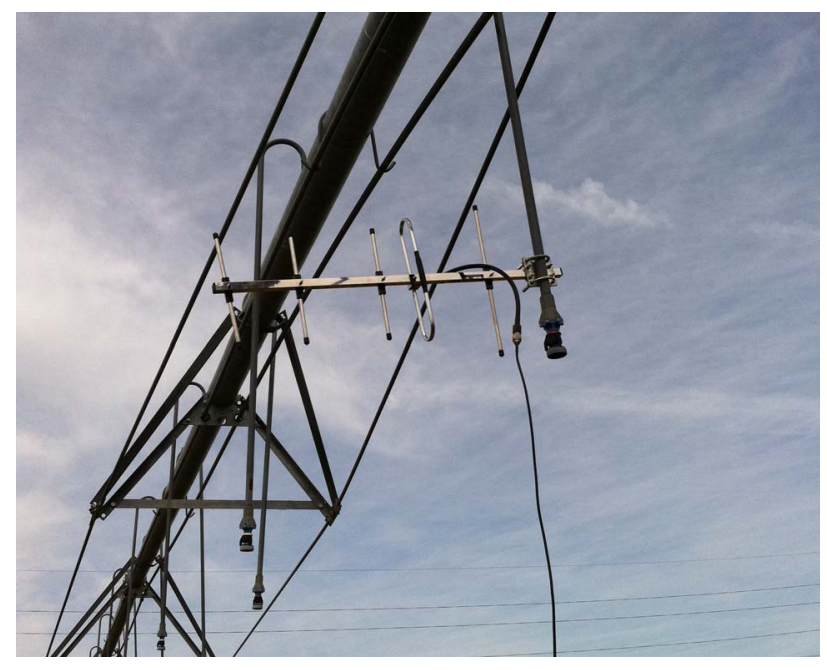

Fig. 4: An aboveground mote attached to the center-pivot.

on the center-pivot. The mote, with its Yagi antenna, is shown in Fig. 4. The SMS messages sent by the aboveground mote are received at the base station and stored in a database.

During the experiments, the underground motes work according to a duty cycle. Each mote sleeps for a period of $T_{s}$ before waking up to take a soil moisture sample. The soil moisture value is written to the flash memory of the mote. In the meantime, The underground mote remains active for a period of $T_{a}$ to listen to the request from the aboveground mote. If there is no request in $T_{a}$, the underground mote turns off its radio and switch to sleeping mode.

When the center-pivot operates in the field, the aboveground mote sends out requests periodically as the center-pivot moves towards underground motes. The interval of the requests, $T_{r}$ is much smaller than $T_{a}$ so that the underground mote can receive at least one request when it is active and the aboveground mote is in its communication range. After receiving the request, the underground mote first replies to the aboveground mote to establish the communication. Then, it reads its flash memory and sends all of the soil moisture recordings to the aboveground mote. Since sending SMS messages is slower than receiving data messages from the underground mote, a buffer is implemented at the aboveground mote to temporarily store the received messages. These messages are then sent out as SMS messages via the GSM module.

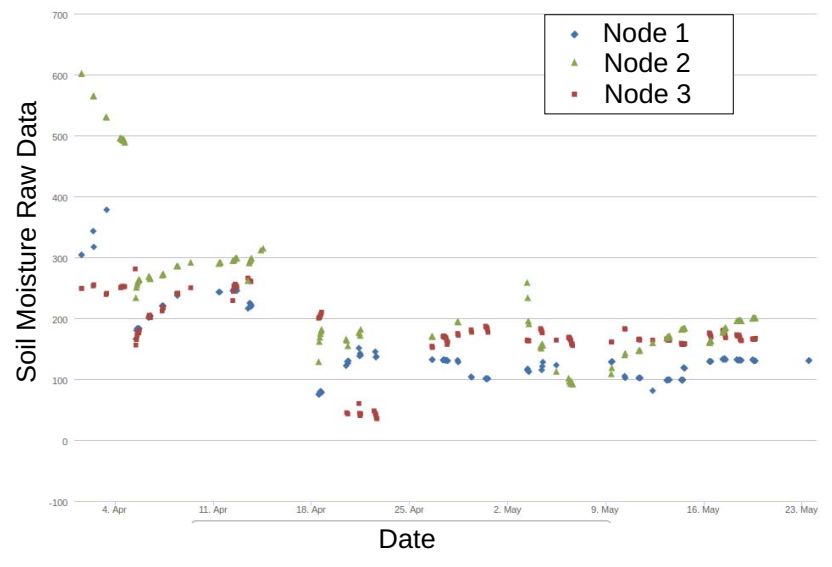

Fig. 5: The display of the soil moisture results.

At the base station, the SMS messages are parsed and the soil moisture values are stored in a database and displayed on a chart. The display is shown in Fig. 5.

\section{CONCLUSIONS}

Being able to dynamically control a center pivot irrigation system allows for a wireless underground sensor network to actuate on the environment. The system presented here fits into the larger, autonomous irrigation system by implementing a wireless connection between WUSN motes and a center pivot irrigation system with an SMS enabled controller. Demonstrations carried out show that by adapting proper APIs with the center-pivot, the system is feasible.

\section{REFERENCES}

[1] CropMetrics. Virtual agronomist. [Online]. Available: http://cropmetrics. $\mathrm{com} / \mathrm{wp}$-content/uploads/va-brochure.pdf

[2] X. Dong, M. C. Vuran, and S. Irmak, "Autonomous precision agricultrue through integration of wireless underground sensor networks with center pivot irrigation systems," Ad Hoc Networks (Elsevier), under review.

[3] H. D. Foth, Fundamentals of Soil Science, 8th ed. John Wiley \& Sons, 1990.

[4] J. Giacomin and F. Vasconcelos, "Wireless sensor network as a measurement tool in precision agriculture," in In Proc. XVIII IMEKO World Congress - Metrology for a Sustainable Development, Rio de Janeiro, Brazil, September 2006.

[5] A. McBratney, B. Whelan, T. Ancev, and J. Bouma, "Future directions of precision agriculture," Precision Agriculture, vol. 6, no. 1, pp. 7-23, 2005.

[6] L. Sha, S. Gopalakrishnan, X. Liu, and Q. Wang, "Cyber-physical systems: A new frontier" in Proc. IEEE International Conference on Sensor Networks, Ubiquitous, and Trustworthy Computing (SUTC 2008), Taichung, Taiwan, June 2008.

[7] J. Tooker and M. C. Vuran, "Mobile data harvesting in wireless underground sensor networks," in IEEE SECON '12, Seoul, Korea, June 2012, to appear.

[8] United Nations, "Coping with water scarcity—challenge of the twentyfirst century," World Water Day 2007 Report, 2007.

[9] UNL Water Center. (2009, Jan.) Top 10 water challenges for Nbraska (2009). [Online]. Available: http://watercenter.unl.edu/ downloads/TopTenJanuary2009.pdf

[10] Valmont Industries. Variable Rate Irrigation. [Online]. Available: http://www.valleyirrigation.com/page. $a s p x ? i d=2342 \&$ pid $=42$

[11] G. Vellidis, M. Tucker, C. Perry, C. Kvien, and C. Bednarz, "A real-time wireless smart sensor array for scheduling irrigation," Computers and Electronics in Agriculture, vol. 61, no. 1, pp. 44-50, 2008. 